\title{
Research On Energy Distribution and Solidification Characteristics During Laser Cladding Based On Numerical Simulation
}

\section{Wenhui Yang}

China University of Mining and Technology

Yanhai Cheng ( $\nabla$ chyh1007@cumt.edu.cn )

China University of Mining and Technology

Yipeng Zhang

China University of Mining and Technology

Jinyong Yang

China University of Mining and Technology

Xiubing Liang

National Defense Science and Technology Innovation Study Institute

\section{Research Article}

Keywords: Laser cladding, Numerical simulation, arbitrary lagrange-euler algorithm, Solidification characteristics, Surface modification

Posted Date: December 15th, 2021

DOI: https://doi.org/10.21203/rs.3.rs-1070134/v1

License: (c) (1) This work is licensed under a Creative Commons Attribution 4.0 International License. Read Full License 


\section{Research on Energy Distribution and Solidification Characteristics During Laser Cladding Based on Numerical Simulation}

Wenhui Yang ${ }^{1}$, Yanhai Cheng ${ }^{1 *}$, Yipeng Zhang ${ }^{1}$, Jinyong Yang ${ }^{1}$, Xiubing Liang ${ }^{2 *}$ 1. School of Mechanical and Electrical Engineering, China University of Mining and Technology, Xuzhou,221116;

2. National Defense Science and Technology Innovation Study Institute, Academy of Military Sciences, Beijing, 100142

* Corresponding author. E-mail address: chyh1007@cumt.edu.cn. (Cheng Yanhai)

* Corresponding author. E-mail address: liangxb_d@163.com. (Liang Xiubing)

Abstract: Laser cladding as an emerging surface modification technology can be widely adopted for surface modification. In this study, 27SiMn was selected as the substrate, the powder was a self-made iron-based alloy, and the thermophysical properties of the material were predicted by the CALPHAD algorithm. The numerical model of the laser cladding process is established by setting reasonable hypothetical condition, initial condition, boundary condition, and solver parameters. In order to verify the accuracy of the numerical model, 10 sets of experiments have been carried out, and the agreement between the model calculation results and the experimental results reached $92 \%$. Through the study of energy distribution in the laser cladding process, it is found that about $10 \%$ of the laser energy is used to heat the substrate to form a melt-pool, and at least 53\% of the energy is radiated into the environment. Finally, the effects of temperature gradient and solidification rate on the microstructure of the cladding layer were explored.

Keywords: Laser cladding, Numerical simulation, arbitrary lagrange-euler algorithm, Solidification characteristics, Surface modification

\section{Introduction}

Laser cladding is one of the additive manufacturing technologies using laser as the heat source. Compared with other additive manufacturing techniques, it holds advantages like high forming precision, small heat affected zone, and easy achievement of automation, and has been widely used in aerospace ${ }^{[1]}$, resource mining ${ }^{[2]}$, the nuclear industry ${ }^{[3]}$ and other industries. 
Because a lot of light and heat would be released during the laser cladding process, in recent years, scholars have begun to use numerical simulation technology to study the temperature and flow of the melt-pool in the laser cladding process. Jiang Yichao $^{[4]}$ used the Finite Volume Method (FVM) to simulate the temperature distribution and fluid flow of the laser cladding process in the form of preset-powder, and studied the influence of the Marangoni effect on the size of the melt-pool. Zhe Sun ${ }^{[5]}$ established a three-dimensional numerical model to study the mass transfer and heat transfer in the melt-pool in the laser molten in 316L stainless steel. However, the author did not consider the attenuation of laser in the laser cladding process. H.L. Wei ${ }^{[6]}$ established a three-dimensional model for coupling simulation of heat transfer and fluid flow, and a two-dimensional model for simulating grain formation in the melt-pool. It shows that the columnar grains grow in a bending mode, and the critical scanning speed of the columnar while transformed into equiaxed crystals was obtained. However, in the research process, the size of the melt-pool was limited in advance, which caused a large deviation between simulation results and experimental results. Wenyan $\mathrm{Gao}^{[7]}$ established a three-dimensional finite element model for simulating the temperature field in the laser cladding process, and used the life and death unit algorithm to represent the formation process of the cladding layer. The instantaneous temperature distribution and temperature curve were obtained, and the solidification and cooling rate of the moving solid-liquid interface and its influence on the microstructure of the cladding layer were systematically analyzed and calculated. Due to the characteristics of the life and death unit algorithm, it is not suitable for predicting the formation process of the cladding layer, which makes the cladding layer model seriously distorted.

In this study, 10 groups of different process parameters laser cladding processes were simulated, and corresponding experiments were conducted to verify the accuracy of simulation results. The effects of process parameters on the laser cladding layer were discussed. The substrate and powder physical properties are associated with temperature, and the temperature physical properties of the desired material were calculated by the CALPHAD algorithm. By measuring the verification of model 
accuracy in the layered contour size, the effects of process parameters on the laser cladding layer are discussed. And a relatively reasonable energy allocation model was obtained after discussing the results of the model calculation, and the effects of temperature gradient and solidification speed on microstructure morphology and size were analyzed.

\section{Experiments}

\subsection{Experimental Materials}

The material of substrate was $27 \mathrm{SiMn}$ in this study, which was the main material of the domestic hydraulic cylinder. The powder material is self-made iron-based alloy powder with particle size distribution of $20-53 \mu \mathrm{m}$, which has good wear resistance, corrosion resistance, and excellent machining properties, and the fluid phase temperature and the expansion coefficient are similar to 27SiMn. Therefore, the powder and the substrate can form a firm metallurgy binding. The element mass fractions of the two materials are shown in Table 1.

The the CALPHAD algorithm is used to calculate the thermophysical properties of the material in this study. Through repeated verification by some scholars ${ }^{[8,9]}$, the calculation result of the CALPHAD algorithm is close to the experimental result. The thermophysical properties of the substrate and powder are shown in Fig.1.

According to the Hagen-Ruben relational formula ${ }^{[10]}$, the laser power absorptivity value of the substrate and powder can be obtained, as shown in eq.(1):

$$
\beta_{s / p}=\left(8 \varepsilon_{0} \varphi R(T)\right)^{1 / 2}
$$

In eq.(1), $\varepsilon_{0}=1 / 36 \pi \times 10^{9} F \cdot m^{-1}, \varphi=2 \pi c / \lambda$, c represents the speed of light in the vacuum; $\lambda$ is the laser wavelength; $R(T)$ represents the resistivity of the material, which is a function that changes with temperature. The laser absorption rate of the substrate is shown in Fig.2. In order to simplify the calculation, a constant is selected as the laser absorptivity value of powder. As the powder falls into the melt-pool in a liquid form, $\beta_{p}$ is taken as 0.47 .

\subsection{Experimental equipment}

The experimental parameters of this study are as shown in Table 2. 
Schematic diagram of laser classes is as shown in Fig.3. In the experiment, in order to explore the mutual coupling of laser and powder and determine the diameter of the powder flow profile, the experimental photo is photographed as shown in Fig. 4 (a)., in which the replacement light is a red light having a power of $5 \mathrm{~W}$. The image recognition algorithm is used to extract the powder flow profile and 11 data points are selected. The establishment of the coordinate system is as shown in Fig. 4 (b), fitted to the expression of $r_{p}$ in the $z$ direction, as in the eq.(2), fitted image as shown in Fig. 4 (c).

$$
r_{p}=0.05 z^{2}-0.28 z+1.38 \quad\left(0 \leq z \leq h_{1}\right)
$$

\subsection{Process parameters}

This study adopts the method of orthogonal experiment, and the process parameters of the experiment were as shown in Table 3. Exp.1, 2, 3, 4 are used to explore the effects of different laser power on laser cladding processes; exp.1, 5, 6, 7 are used to explore the effects of different delivery rates on laser cladding processes; exp.1, 8, 9, 10 are used to explore the effects of different scanning speed on the laser cladding process. The size of the substrate is $300 \mathrm{~mm} \times 300 \mathrm{~mm} \times 20 \mathrm{~mm}$, and the room temperature is $298 \mathrm{~K}$. Before the experiment, the powder was dried at $373 \mathrm{~K}$ for 2 hours.

\subsection{Experimental detection}

The cladding layers of the 10 groups of experiments were made into 10 sample blocks with a size of $10 \mathrm{~mm} \times 10 \mathrm{~mm} \times 15 \mathrm{~mm}$, and the cross-section of those cladding layers were ground, polished, corroded, and cleaned. The height and width of the cladding layer were observed under a metallographic microscope, and the microstructure was photographed with a scanning electron microscope (SEM).

\section{Simulation}

The use of numerical simulation in the field of engineering study is increasing. The content of the simulation is based on basic control equations, set of reasonable assumptions, initial conditions and boundary conditions, so the numerical model is both efficient and realistic. 


\subsection{Assumptions}

Appropriate assumptions can reduce the nonlinearity of the numerical model and enhance convergence. The basic assumptions in this study are:

1. The liquid metal in the melt-pool is Newtonian, incompressible, laminar fluid.

2. Laser, and powder flow complies with the Gaussian distribution, the powder flow profile is not affected by the powder feeding rate, and the particles in the air do not block or collide with each other.

3. Ignore the energy loss caused by evaporation.

4. The mushy zone between the solid line and the liquid line of the melt-pool is assumed to be isotropic porous medium.

5. The powder is a standard sphere and is heated evenly.

6. Ignore the laser energy entering the melt-pool through the reflection of powder particles.

\subsection{Governing equation}

The mass conservation equation ${ }^{[11]}$ is as in eq.(3):

$$
\frac{\partial \rho}{\partial t}+\nabla \cdot(\rho v)=S_{\text {mass }}
$$

The energy conservation equation is as in eq.(4):

$$
\begin{gathered}
\rho C_{p} \frac{\partial T}{\partial t}+\rho C_{p} v \cdot \nabla T+\nabla(-k \nabla T)=Q-Q_{p}- \\
Q_{v d}
\end{gathered}
$$

In eq. (3), $S_{\text {mass }}$ represents the added powder mass; in eq. (4), the first term on the left is the transient heat transfer, the second term is the convective heat transfer, and the third term is the conduction heat transfer. The first term on the right is the heat source, the second term is the convection heat transfer with the outside, and the third term is the surface heat radiation.

The momentum conservation equation (Navier-Stokes equation) is as eq.(5):

$$
\rho \frac{\partial v}{\partial t}+\rho(v \cdot \nabla) v=\nabla\left(\mu\left(\nabla v+(\nabla v)^{T}\right)-p I\right)+F
$$

In eq.(5), the left side represents the inertial force, the first term on the right represents the viscous force and pressure, and the second term on the right represents the volume force of the liquid in the melt-pool. 


\subsection{Initial conditions}

In order to save computational cost, a symmetric method is adopted to simplify the numerical model. A rectangular parallelepiped model with a size of $10 \mathrm{~mm} \times 4 \mathrm{~mm} \times 4 \mathrm{~mm}$ is established and divided into two calculation domains. The shape of calculation domain $A$ is $10 \mathrm{~mm} \times 1.5 \mathrm{~mm} \times 1.5 \mathrm{~mm}$. The mesh type is a free tetrahedral mesh. And computational domain A is the main area for melt-pool calculation. The required accuracy is high. The maximum element size is $0.2 \mathrm{~mm}$; Computational domain B is only used for heat transfer calculations, and the maximum element size is set to be $0.4 \mathrm{~mm}$. As shown in Fig. 5 .

The parameters of the model are as follows: initial temperature $\mathrm{T}_{0}=298 \mathrm{~K}$, external pressure $\mathrm{P}_{0}=1[\mathrm{~atm}]$, material convection velocity $\mathrm{V}_{0}=0 \mathrm{~m} / \mathrm{s}$, initial displacement $\mathrm{d}_{0}=0 \mathrm{~m}$, and the concentration of each element of the substrate material is set as the initial concentration.

\subsection{Boundary conditions}

\subsubsection{Thermal boundary conditions}

The laser will pass through the powder flow before reaching the substrate, and the powder flow will attenuate the laser energy. Attenuation is caused by the combined effects of powder particles on laser energy absorption, diffraction, transmission and refraction, and reflection ${ }^{[12]}$. At the same time, the powder absorbs laser energy to increase its internal energy and change its physical state. Before reaching the substrate, the powder particles move in a straight line at a uniform speed. The speed is the same as the vertical speed component of the powder-carrying gas at the outlet, and the speed direction is perpendicular to the surface of the substrate.

The concentration of powder flow in space is as eq.(6) ${ }^{[13]}$ :

$$
C(x, y, z)=\frac{27 m_{f}}{8 \pi^{2} r_{0}{ }^{3} \rho_{p} r_{p}{ }^{2} v_{z}} \exp \left(-\frac{9\left(x^{2}+y^{2}\right)}{2 r_{p}{ }^{2}}\right)
$$

The shading area of powder particles is shown in eq.(7):

$$
=2 \pi r_{0}^{2}
$$

The powder speed is as in eq. (8), and $\theta$ is the angle between the outlet of the 
powder-carrying gas and the vertical direction.

$=\frac{V}{\pi\left(R_{1}^{2}-R_{2}^{2}\right)} \sin \theta$

The laser utilization rate is as in eq. (9) ${ }^{[14]}$ :

$$
\eta=\exp \left(-\frac{3 m_{f} S_{p}}{4 \pi^{2} r_{0}^{3} \rho_{p} r_{p 0}^{2} v_{z}} \int_{0}^{h_{1}}\left(1-\exp \left(-\frac{9 r_{p 0}^{2}}{2 r_{p}^{2}}\right)\right) d z\right)
$$

The average temperature $T_{i}$ of the powder before falling into the melt-pool is as in eq. (10):

$=\frac{(1-\eta) P_{0} \beta_{p}}{m_{f} C_{P_{-} p}}$

$+T_{0}$

The initial energy of the laser is as in eq. (11):

$$
Q_{0}=\frac{2 P_{0}}{\pi \times r_{l}^{2}} \exp \left(\frac{-2\left(x^{2}+y^{2}\right)}{r_{l}^{2}}\right)
$$

The heat source formula added on the surface of the model is as in eq. (12) ${ }^{[15]}$ :

$$
\begin{aligned}
Q_{s}= & \frac{2 P_{0} \eta \beta_{s}}{\pi r_{l}^{2}} \exp \left(\frac{-2\left(\left(x-v_{x} t\right)^{2}+y^{2}\right)}{r_{l}^{2}}\right) \\
& -\frac{2 m_{f} \eta_{p}}{\pi r_{p}{ }^{2}}\left(L_{H}+C_{P}\left(T-T_{i}\right)\right) \exp \left(\frac{-2\left(\left(x-v_{x} t\right)^{2}+y^{2}\right)}{r_{p}^{2}}\right)
\end{aligned}
$$

$f_{l}$ is the liquid volume fraction, defined as in eq.(13):

$$
=\left\{\begin{array}{lr}
1, & T_{l}<T \\
\frac{T-T_{s}}{T_{l}-T_{s}}, & T_{s}<T<T_{l} \\
0, & T_{0}<T<T_{s}
\end{array}\right.
$$

In eq. (13), $T_{0}$ is the ambient temperature; $T_{s}, T_{l}$ are the solidus and liquidus temperatures of the material, respectively

When the temperature is between the solidus temperature and the liquidus temperature, the metal material is in a molten state, and the thermophysical properties 
of the material in this region are as shown in eq.(14) eq.(17).

$=\left(1-f_{l}\right) \rho_{s}$

$+f_{l} \rho_{l}$

$=\left(1-f_{l}\right) k_{s}$

$+f_{l} k_{l}$

$=\frac{1}{2} \frac{f_{l} \rho_{l}-\left(1-f_{l}\right) \rho_{s}}{\left(1-f_{l}\right) \rho_{s}+f_{l} \rho_{l}}$

$\alpha_{m}$

$C_{p}=\frac{1}{\rho}\left(\left(1-f_{l}\right) \rho_{s} C_{p s}+f_{l} \rho_{l} C_{p l}\right)$

$+L_{H} \frac{\partial \alpha_{m}}{\partial T}$

When the temperature of the substrate rises, it will form heat convection with the surrounding air and generate heat radiation to the environment, as shown in eq. (18) and eq. (19) respectively,

$=h(T$

$\left.-T_{0}\right)$

$=\varepsilon \sigma\left(T^{4}-T_{0}^{4}\right)$

$Q_{v d}$

$h$ is the convective heat transfer coefficient, which takes $0.7 ; \varepsilon$ is surface emissivity; $\sigma$ is Stepan Boltzmann's constant, the value is $5.67 \times 10^{-8} \mathrm{~W} /\left(\mathrm{m}^{2} \cdot \mathrm{K}^{4}\right)$

\subsubsection{Fluid boundary conditions}

The volume force received by the liquid in the melt-pool in eq.(5) can be expanded to eq.(20):

$$
F=-\rho g+\alpha\left(T-T_{l}\right) \rho g-K_{0} \frac{\left(1-f_{l}\right)^{2}}{f_{l}^{3}+m} v
$$

In the formula, the first term on the right represents gravity; the second term on the right represents thermal buoyancy, $\alpha$ is the thermal expansion coefficient of the mixed material in the melt-pool, and the direction is vertically upward; the third term 
on the right represents the Momentum dissipation of the porous media layer between the solid phase and the liquid phase on the liquid metal in the melt-pool, where $\mathrm{K}_{0}$ takes the larger value, $10^{6} \mathrm{~kg} /\left(\mathrm{m}^{3} \cdot \mathrm{s}\right)$; and in order to avoid division by zero errors, $\mathrm{m}$ takes the smaller value, $10^{-4[16]}$.

On the surface of the melt-pool, the liquid metal is subject to surface tension. The surface tension coefficient is a physical quantity that changes with temperature and concentration. In this study, the influence of concentration changes on surface tension is not considered. The curve of the surface tension coefficient with temperature can be obtained based on the CALPHAD algorithm, as shown in Fig.6. It can be seen from Fig. 6 that the higher the temperature, the smaller the surface tension coefficient, that is, the surface tension temperature coefficient is negative. Since the temperature decreases from the center of the melt-pool to the edge, the surface tension also decreases from the center of the melt-pool to the edge, forming a surface tension gradient. The liquid flows from the direction of low surface tension to high tension, thereby driving the transmission of mass. This phenomenon is called the Marangoni effect.

As a dimensionless number, the Marangoni number is proportional to the ratio of the surface tension divided by the viscous force, indicating the degree of the Marangoni effect on the flow of liquid metal.

$$
=-\frac{d \gamma}{d T}
$$$$
\cdot \frac{L \Delta T}{\mu \alpha}
$$

$\mathrm{d} \gamma / \mathrm{dT}$ is the temperature coefficient of surface tension, $\mathrm{L}$ is the characteristic length, $\mu$ is the dynamic viscosity, and $\Delta \mathrm{T}$ is the maximum temperature difference in the melt-pool.

The force on the surface of the melt-pool is as follows (22): 
$=\gamma n_{m} \kappa$

$-\frac{d \gamma}{d T} \nabla_{t} T$

$\gamma$ is the surface tension coefficient, $n_{m}$ is the normal vector of the melt-pool surface, $\kappa$ is the average curvature of the melt-pool surface, and $\nabla_{t}$ is the tangential guide number operator of the melt-pool surface.

\subsubsection{Mass transfer boundary conditions}

In the numerical simulation, the adding process of powder can be resolved into volume change and element change. The volume change is characterized by the dynamic grid algorithm, and the element change is represented by the matter flux equation. The transmission speed of the element and the velocity field are set in a coupling relationship.

The material flux ${ }^{[17]}$ on the surface of the melt-pool is as in eq. (23):

$$
q_{i}=\omega_{i} \frac{2 m_{f} \eta_{m}}{M_{i} \pi r_{p}^{2}} \exp \left(\frac{-2\left(\left(x-V_{x} t\right)^{2}+y^{2}\right)}{r_{p}{ }^{2}}\right)
$$

During the cladding process, the powder falls into the melt-pool and fully mixes with the substrate under the action of the Marangoni effect. Therefore, the thermophysical properties of the liquid metal in the melt-pool are determined by the properties of the substrate and the powder.

$$
P=P_{p} \times \sigma_{p}+P_{s} \times\left(1-\sigma_{p}\right)
$$

In eq.(24) ${ }^{[18]}$, P represents the thermophysical properties of the model, including density, thermal conductivity, dynamic viscosity, constant pressure heat capacity, surface tension coefficient, etc., $P_{s}$ and $P_{p}$ represent the thermophysical properties of the powder and the substrate, respectively. $\sigma_{p}$ represents the degree of powder mixing in the melt-pool, and is calculated by eq.(25) ${ }^{[16]}$ :

$$
\sigma_{p}=\frac{c_{F e}-c_{F e_{-} s}}{c_{F e_{-} p}-c_{F e_{-} s}} \times 100 \%
$$

$c_{F e}$ represents the iron element concentration of the model in the transient calculation process, $c_{F_{e} s}$ and $c_{F e_{-} p}$ represent the initial iron element concentration in the substrate and powders respectively, the unit is $\mathrm{mol} / \mathrm{m}^{3}$. 


\subsubsection{Mesh boundary conditions}

The algorithms currently used to represent volume changes mainly include life and death units ${ }^{[7,19]}$, level sets ${ }^{[20]}$, and the Arbitrary Lagrangian Eulerian (ALE) moving mesh approach ${ }^{[21]}$. Given that the forming accuracy of the life and death unit algorithm is low, the level set algorithm is complex and is difficult to set, while the moving grid algorithm is simple to set up and can form a more accurate interface, the dynamic grid algorithm is used to characterize the formation of the cladding layer.

The moving speed of the melt-pool surface is mainly affected by the addition of powder and the flow of liquid metal in the melt-pool, therefore in the ALE moving mesh approach, the moving speed of the melt-pool surface ${ }^{[21]}$ is

$$
V_{s}=V_{p} \cdot n_{m}+v \cdot n_{m}
$$

In eq.(26), $V_{s}$ is the moving speed of the melt-pool surface, $V_{p}$ is the moving speed of the melt-pool surface due to powder addition, $v$ is the flow velocity of the liquid metal on the melt-pool surface, and $n_{m}$ represents the unit normal vector of the melt-pool surface.

The moving speed of the melt-pool surface due to powder addition is

$$
V_{p}=\frac{2 m_{f} \eta_{p}}{\rho_{p} \pi r_{p 0}^{2}} \exp \left(\frac{-2\left(\left(x-V_{x} t\right)^{2}+y^{2}\right)}{r_{p}^{2}}\right) \cdot z_{m}
$$

In eq.(27), $\eta_{p}$ is the powder utilization rate, $\rho_{p}$ is the density of the powder, $r_{p 0}$ is the radius of the powder flow on the substrate, and $z_{m}$ is the unit vector in the $\mathrm{z}$ direction

\section{Results and discussion}

\subsection{The results of numerical calculation}

A heat source is applied on the upper surface of the model, initial conditions and boundary conditions are given in 2.4.1, and the temperature field at different times is obtained.

Temperature distribution at different times is as shown in Fig.7. At the initial stage of laser cladding, the laser starts to heat the substrate, the melt-pool has not been formed at this time, and the temperature is reduced from the center to the surrounding. When the local temperature is higher than the material liquid phase line temperature, 
the substrate changes into a melt-pool. As the powder continues to accumulate in the melt-pool, the model surface begins to deform. As the laser beam moves in the scanning direction, the temperature gradient in the melt-pool exhibits high front end and low back ends.

Fig. 8 is the distribution profile of velocity at different times. At the initial stage of melt-pool formation, the liquid metal in the melt-pool does not flow. As the temperature increases, the volume of melt-pool expands, and the liquid metal in the melt-pool flows under the action of surface tension, gravity and thermal buoyancy. Because the temperature coefficient of surface tension is negative, the liquid metal on the melt-pool surface flows from the center to the edge under the influence of Marangoni effect. Due to the existence of gravity and thermal buoyancy, liquid metal flows into the bottom of the melt-pool along the solidification interface, and then rises to the surface of the melt-pool, forming eddy current from inside to outside. Under the action of eddy current, wide and shallow melt-pool is formed. As the melt-pool moves, the temperature rises and the shape of the melt-pool gradually changes from a semicircle to an ellipsoid. The flow velocity in the melt-pool accelerates until it becomes stable. As shown in Fig.8, the white line segment represents the liquid and solid phase lines of the model, and the arrow represents the flow direction of liquid metal in the melt-pool. The velocity direction is consistent with the research results of Acharya et al. ${ }^{[22]}$, and the value is of the same order of magnitude.

When the model of exp.1 was calculated to $100 \mathrm{~ms}$, the temperature and velocity distribution curves of the melt-pool surface along the scanning velocity direction are as shown in Fig.9.

It can be seen from Fig. 8 and 9 that the flow rate of liquid metal on the melt-pool surface presents a hump distribution, and the flow rate at the bottom of the melt-pool is lower than that on the melt-pool surface, and the maximum velocity in the melt-pool is $0.25 \mathrm{~m} / \mathrm{s}$. Marangoni effect plays an important role in promoting the flow of liquid metal in the melt-pool. The greater the temperature gradient, the more intense the Marangoni effect, and thus the greater the acceleration. The flow at the bottom of the melt-pool is affected by the process of cellular crystal forming, resulting 
in momentum loss. The liquid metal at the bottom of the pool flows upward under the action of thermal buoyancy. The velocity at the center of the melt-pool surface is close to that at the bottom of the pool because the thermal buoyancy is not sufficient to produce large flow acceleration.

\subsection{Comparison of external dimensions}

Comparing the profile size of cladding layer is the most intuitive and simplest method to verify the model accuracy. Fig.10 shows the dimensions of the cross section obtained by experiment and simulation.

It can be seen from Fig. 10(b) that when only the laser power is changed, the height of the cladding layer hardly changes, and the width increases with the increase of the laser power. The reason is that with the laser power becoming larger, the energy irradiated to the surface of the substrate increases, the temperature at the center of the melt-pool increases, and the width of the melt-pool becomes larger. While the height of the cladding layer is mainly related to the amount of powder falling into the melt-pool, so under the premise of constant powder feeding rate, the height of the center of the cladding layer remains unchanged.

It can be seen from Fig.10(c) that when only the powder feeding rate is changed, the width of the cladding layer has no obvious trend. Although in theory, the larger the powder feeding rate, the smaller the laser attenuation rate, in this experiment, the change in the attenuation rate caused by the change in the powder feeding rate is not obvious. The height of the cladding layer decreases significantly as the powder feeding rate decreases.

It can be seen from Fig. 10(d) that when only the scanning speed is changed, the width and height of the cladding layer have obvious changes. The increase of scanning speed will lead to the decrease of the instantaneous energy density and instantaneous powder concentration on the substrate, which will form a narrow and long melt-pool. The scanning speed should be selected in an appropriate interval. When the scanning speed is too high, the material on the surface of the substrate cannot be melted sufficiently, forming a cladding layer with poor bonding, or even no cladding layer. When the scanning speed is too low, disordered accumulation of 
powder will be caused.

As can be seen from Fig.10, the height of the layer obtained by simulation is greater than the experimental measurement, and the width is slightly smaller. In the study, in order to reduce the degree of nonlinearity of the model, the dynamic viscosity of the liquid metal in the melt-pool is limited, resulting in deterioration of fluidity, so the width of the molten coating layer of the simulation will be smaller; During the laser cladding experiment, the powder is ejected from the nozzle, which causes some powder loss, and this phenomenon is ignored in the simulation, so the high degree of simulation is slightly higher than the height measured by the experiment. The maximum error of the experimental measured shape and simulation calculation is $8 \%$, indicating the rationality of three-dimensional laser cladding model.

\subsection{Energy distribution}

The energy transfer process of laser cladding is shown in Fig.11.

The initial energy $Q_{0}$ output by the laser reaches the surface of the substrate after the attenuation of the powder. However, not all the attenuated energy will be absorbed by the substrate material, the substrate has a certain absorption rate $\beta_{s}$ of laser energy, which is related to the resistivity of the material and the laser wavelength. During the experiment, the laser wavelength is a constant, the material resistivity is a physical property related to temperature, and the laser absorption rate of the substrate is as shown in Fig.2. Part of the energy attenuated by the powder is absorbed by the powder, and the rest is released to the outside world through refraction, scattering, and reflection. Only the powder falling into the melt-pool can play a role in the formation of the cladding layer, so the powder utilization rate $\eta_{p}$ represents the ratio of the amount of powder falling into the melt-pool to the total amount of powder.

The laser energy absorbed according to Fig.11 is as shown in eq.28:

$$
Q_{s}=Q_{0} \eta \beta_{s}
$$

According to eq.9, the laser utilization $\eta=0.2$ is obtained. According to Fig.2, it is known that the laser absorption rate of the substrate is $\beta_{\mathrm{s}}=0.475$, so $\mathrm{Q}_{\mathrm{s}} \approx 0.10 \mathrm{Q}_{0}$, that is $10 \%$ of the laser energy in exp. 1 is used to heat the substrate to form a melt-pool. 
During the transmission of laser energy, the dissipative energy is as shown in eq.29:

$$
Q_{\text {loss }}=Q_{0}\left(\eta\left(1-\beta_{s}\right)+(1-\eta)\left(1-\beta_{p}\right)+(1-\eta) \beta_{p}\left(1-\eta_{p}\right)\right)
$$

When powder utilization $\eta_{\mathrm{p}}=1, \mathrm{Q}_{\mathrm{loss}} \approx 0.53 \mathrm{Q}_{0}$ is calculated, that is at least $53 \%$ of the laser energy in the cladding process is released into the environment.

The thermal input in the melt-pool is as shown in eq.30:

$=Q_{0}\left(\eta \beta_{s}\right.$

$\left.+(1-\eta) \beta_{p} \eta_{p}\right)$

After analysis and calculation, it is found that the energy for heating the substrate to form the fuse pool only accounts for $10 \%$ of the laser output energy; about $53 \%$ of energy is consumed. The research results of Gedda et al. ${ }^{[13]}$ have proved this conclusion.

\subsection{Solidification characteristics}

The laser cladding process needs to undergo rapid heating and cooling. In this process, the temperature gradient $(\mathrm{G})$ and the solidification speed (S) on the solidification interface are two crucial parameters. The changes of $\mathrm{G}$ and $\mathrm{S}$ will directly affect the microstructure of the cladding layer, and then affect the surface quality of the cladding layer. The influence of $\mathrm{G}$ and $\mathrm{S}$ on the microstructure is as shown in Fig. $12^{[23]}$.

$\mathrm{G} \times \mathrm{S}$ is defined as the cooling rate, which directly determines the size of microstructure grains. The faster the cooling rate, the finer the microstructure grains. The value of $\mathrm{G} / \mathrm{S}$ determines the microstructure morphology. As G/S gradually increases, the microstructure morphology changes from cellular to equiaxed dendritic.

The directions of $\mathrm{G}$ and $\mathrm{S}$ are perpendicular to the solidification interface, and the expressions are respectively ${ }^{[24]}$ :

$=\|\nabla \mathrm{T}\|$ 
$\mathrm{S}=v_{x} \cos \delta=v_{x} \frac{-\partial T / \partial x}{\mathrm{G}}$

In eq.(31), $\delta$ represents the angle between the normal vector of the solidification interface and the scanning speed direction on the vertical plane. The minimum of which at the top of the cladding layer is almost $0^{\circ}$, and the maximum at the bottom is $90^{\circ}$, so the solidification speed at the top is most close to the scanning speed, and the minimum at the bottom is $0 \mathrm{~m} / \mathrm{s}$. The projection diagram of the solidification interface on the melt-pool symmetry is as shown in Fig.13.

The simulation result when the time is $200 \mathrm{~ms}$ in exp. 1 is selected, and the size of $\mathrm{G}$ and $\mathrm{S}$ on the solidification interface is projected on a two-dimensional plane, as shown in Fig. 14.

As can be seen from Fig.14 (a), G gradually increases from the top of the center of the solidification interface, and the variable region is at the edge; As can be seen from Fig.14 (b), S gradually decreases from the top of the center of the solidification interface.

The sample of exp.1 was selected for line cutting, grinding, etching, and the microstructure of the cladding layer under the SEM is as shown in Fig.15. From the top to the bottom of the molten coating symmetry, isometric measuring points $\mathrm{A}, \mathrm{B}, \mathrm{C}$ are selected. From point A to point C, G×S decreases from $9456 \mathrm{~K} / \mathrm{s}$ from $1978 \mathrm{~K} / \mathrm{s}$, and the microstructure grain gradually becomes larger; G/S increases from $66 \mathrm{Ks} / \mathrm{mm}^{2}$ to $495 \mathrm{Ks} / \mathrm{mm}^{2}$, and the microstructure is transformed from equiaxed dendritic to cellular. The experimental results are highly consistent with the simulation results, and the model has high reliability.

\section{Conclusion}

1. This study established a multi-physical field coupling non-organized three-dimensional numerical model. Based on energy conservation, matter conservation and momentum conservation, the thermal transfer phenomenon of the cladding process is simulated, in which the ALE method is used to characterize the formation process of the cladding layer. The accuracy of the model was found to be $92 \%$ by comparing the 10 sets of experimental results with the molten layers in the 
simulation results.

2. The transfer process of laser energy during laser cladding was explored. After light powder coupling, the laser output energy is simply understood as the process of heating the substrate and the powder respectively. For limit of laser wavelength, laser absorption of the substrate and the powder is limited, thus a lot of energy cannot be absorbed. It could be concluded from research content that: $10 \%$ of laser energy is used to heat the melt-pool; and about $53 \%$ of laser energy is emitted divergently into the environment.

3. The microstructure can be predicted by numerical simulation. When the laser power is $1.9 \mathrm{~kW}$, the powder feeding rate is $11.4 \mathrm{~g} / \mathrm{min}$, and the scanning speed is $1500 \mathrm{~mm} / \mathrm{min}$, from point $A$ to point $C$ on the cross section of the molten layer, $G \times S$ decreases from $9456 \mathrm{~K} / \mathrm{s}$ to $1978 \mathrm{~K} / \mathrm{s}$, and the microstructure size gradually becomes larger; G/S increases from $66 \mathrm{Ks} / \mathrm{mm}^{2}$ to $495 \mathrm{Ks} / \mathrm{mm}^{2}$, and the microstructure is transformed into a column crystal. The value of $\mathrm{G} \times \mathrm{S}$ is negatively correlated with microstructure size, and G/S determines the change of microstructure.

\section{Availability of data and materials}

The findings of this work are available within the article.

\section{Acknowledgements}

This research was supported by the National Major Study and Development Project of China (2018YFC1902400) and the National Natural Science Foundation of China(51676205)

\section{Author information}

Affiliations

1. School of Mechanical and Electrical Engineering, China University of Mining and Technology, Xuzhou,221116.

Wenhui Yang, Yanhai Cheng, Yipeng Zhang, Jinyong Yang

2. National Defense Science and Technology Innovation Study Institute, Academy of Military Sciences, Beijing, 100142. 
Xiubing Liang

\section{Corresponding author}

Correspondence to Yanhai Cheng and Xiubing Liang.

\section{Declaration of Competing Interest}

The authors declare that they have no known competing financial interests or personal relationships that could have appeared to influence the work reported in this paper.

\section{Rights and permissions}

Reprints and Permissions 


\section{References}

[1] Alexandru Pascu, Rosca Julia-Mirza, Stanciu Elena-Manuela. Laser cladding: from experimental research to industrial applications[J]. Materials today : proceedings, 2019, 191059-1065.

[2] J-M Amado, Tobar M-J, Alvarez J-C, et al. Laser cladding of tungsten carbides (Spherotene ${ }^{\circledR}$ ) hardfacing alloys for the mining and mineral industry[J]. Applied Surface Science, 2009, 255(10): 5553-5556.

[3] T Baldridge, Poling G, Foroozmehr E, et al. Laser cladding of Inconel 690 on Inconel 600 superalloy for corrosion protection in nuclear applications[J]. Optics and Lasers in Engineering, 2013, 51(2): 180-184.

[4] Yichao Jiang, Cheng Yanhai, Zhang Xiancheng, et al. Simulation and experimental investigations on the effect of Marangoni convection on thermal field during laser cladding process[J]. Optik, 2020, 203164044.

[5] Zhe Sun, Guo Wei, Li Lin. Numerical modelling of heat transfer, mass transport and microstructure formation in a high deposition rate laser directed energy deposition process[J]. Additive Manufacturing, 2020, 33101175.

[6] H-L Wei, Elmer J-W, DebRoy T. Origin of grain orientation during solidification of an aluminum alloy[J]. Acta Materialia, 2016, 115123-131.

[7] Wenyan Gao, Zhao Shusen, Wang Yibo, et al. Numerical simulation of thermal field and Fe-based coating doped Ti[J]. International Journal of Heat and Mass Transfer, 2016, 9283-90.

[8] Jooyoung Park, Lee Sangbong, Kang Singon, et al. Complex effects of alloy composition and porosity on the phase transformations and mechanical properties of powder metallurgy steels[J]. Powder Technology, 2015, 284459-466.

[9] Shuang Liu, Long Mujun, Zhang Siyuan, et al. Study on the prediction of tensile strength and phase transition for ultra-high strength hot stamping steel[J]. Journal of Materials Research and Technology, 2020, 9(6): 14244-14253.

[10] J Xie, Kar A, Rothenflue J-A, et al. Temperature-dependent absorptivity and cutting capability of CO2 , Nd:YAG and chemical oxygen-iodine lasers[J]. Journal of Laser Applications, 1997, 9(2): 77-85.

[11] Shaoyi Wen, Shin Yung-C. Modeling of transport phenomena in direct laser deposition of metal matrix composite[J]. International Journal of Heat and Mass Transfer, 2011.

[12] H Gedda, Powell J, Wahlstrom G, et al. Energy redistribution during $\mathrm{CO} 2$ laser cladding[J]. JOURNAL OF LASER APPLICATIONS, 2002, 14(2): 78-82.

[13] Zhengtao Gan, Yu Gang, He Xiuli, et al. Numerical simulation of thermal behavior and multicomponent mass transfer in direct laser deposition of Co-base alloy on steel[J]. International Journal of Heat and Mass Transfer, 2017, 10428-38.

[14] Liaoyuan Chen, Zhao Yu, Song Boxue, et al. Modeling and simulation of 3D geometry prediction and dynamic solidification behavior of Fe-based coatings by laser cladding[J]. Optics \& Laser Technology, 2021, 139107009.

[15] Youxiang Chew, Pang John-Hock-Lye, Bi Guijun, et al. Thermo-mechanical model for simulating laser cladding induced residual stresses with single and multiple clad beads[J]. Journal of materials processing technology, 2015, 22489-101.

[16] Alireza Bahrami, Helenbrook Brian-T, Valentine Daniel-T, et al. Fluid flow and mixing in linear 
GTA welding of dissimilar ferrous alloys[J]. International Journal of Heat and Mass Transfer, 2016, 93729-741.

[17] Zhengtao Gan, Liu Hao, Li Shaoxia, et al. Modeling of thermal behavior and mass transport in multi-layer laser additive manufacturing of Ni-based alloy on cast iron[J]. International Journal of Heat and Mass Transfer, 2017, 111709-722.

[18] Chang Li, Yu Zhi-Bin, Gao Jing-Xiang, et al. Numerical simulation and experimental study on the evolution of multi-field coupling in laser cladding process by disk lasers[J]. Welding in the World, 2019, 63(4): 925-945.

[19] V Fallah, Amoorezaei M, Provatas N, et al. Phase-field simulation of solidification morphology in laser powder deposition of Ti - Nb alloys[J]. Acta Materialia, 2012, 60(4): 1633-1646.

[20] X He, Mazumder J. Transport phenomena during direct metal deposition[J]. Journal of applied physics, 2007, 101(5): 53113.

[21] Jie Song, Chew Youxiang, Bi Guijun, et al. Numerical and experimental study of laser aided additive manufacturing for melt-pool profile and grain orientation analysis[J]. Materials \& Design, 2018, 137286-297.

[22] Ranadip Acharya, Bansal Rohan, Gambone Justin-J, et al. A Coupled Thermal, Fluid Flow, and Solidification Model for the Processing of Single-Crystal Alloy CMSX-4 Through Scanning Laser Epitaxy for Turbine Engine Hot-Section Component Repair (Part I)[J]. Metallurgical and Materials Transactions B, 2014, 45(6): 2247-2261.

[23] Welding metallurgy and weldability of nickel-base alloys. Portland: Ringgold, Inc, 2009.

[24] Jiaxin Zhao, Wang Gang, Wang Xiangyu, et al. Multicomponent multiphase modeling of dissimilar laser cladding process with high-speed steel on medium carbon steel[J]. International Journal of Heat and Mass Transfer, 2020, 148118990. 

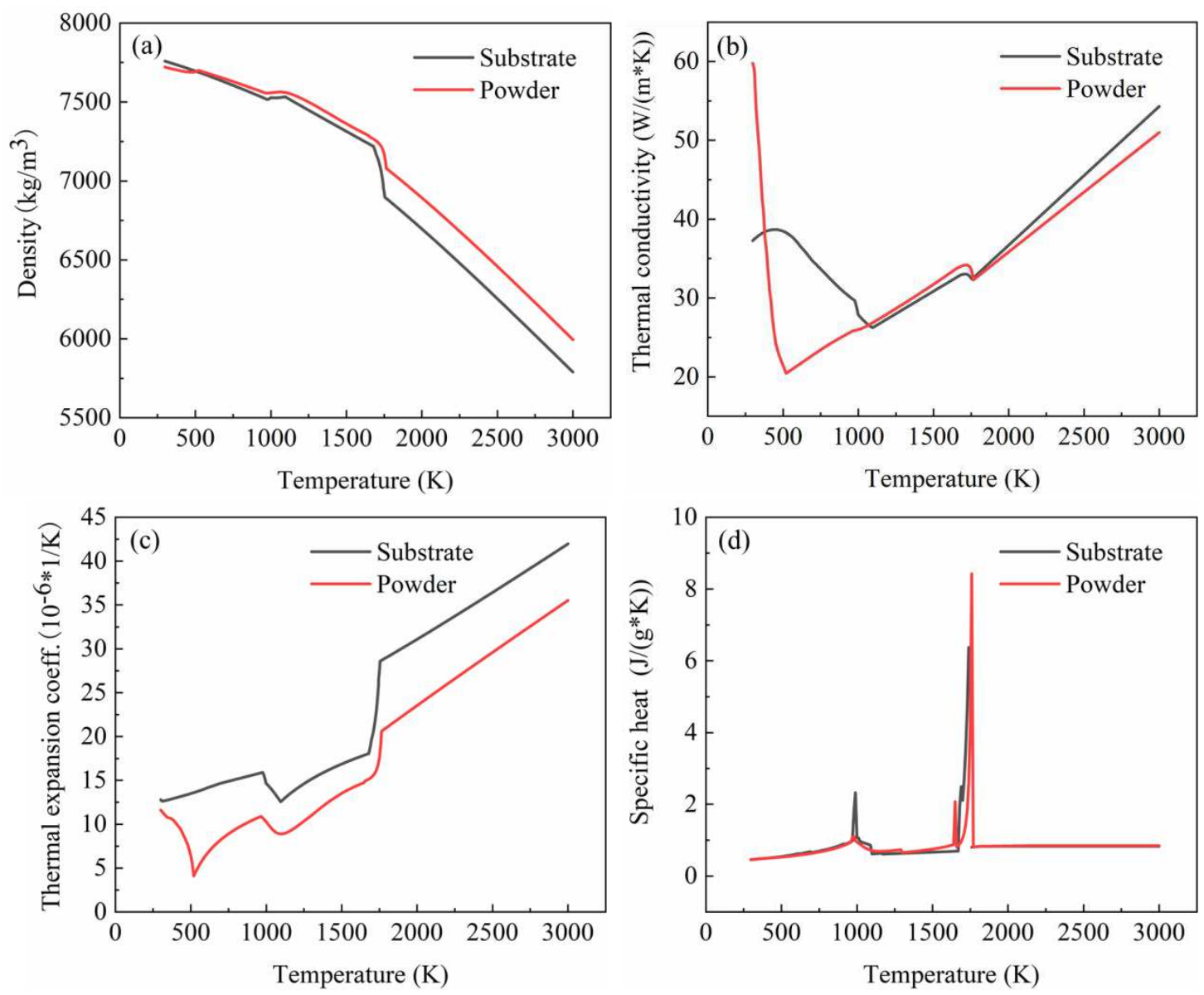

Fig.1 Thermophysical properties of substrate and powder (a) density (b) thermal conductivity (c) thermal expansion coefficient (d) constant pressure heat capacity 


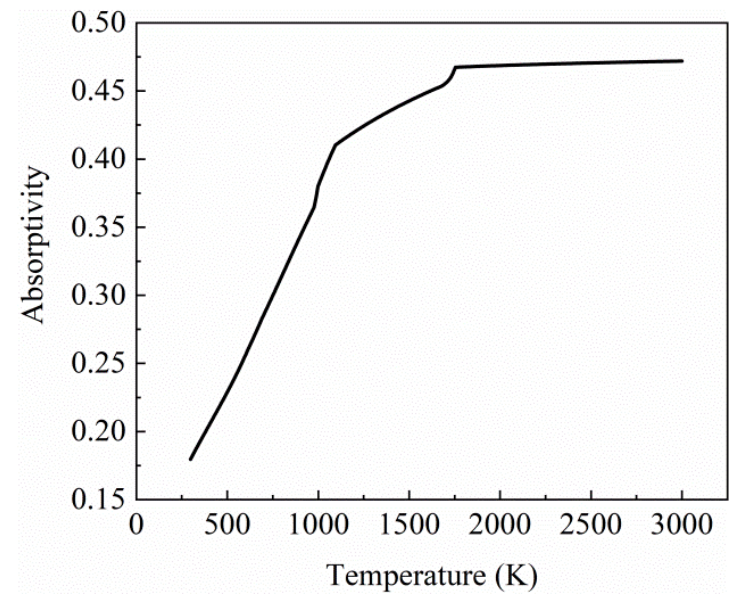

Fig.2 Laser absorption of the substrate 


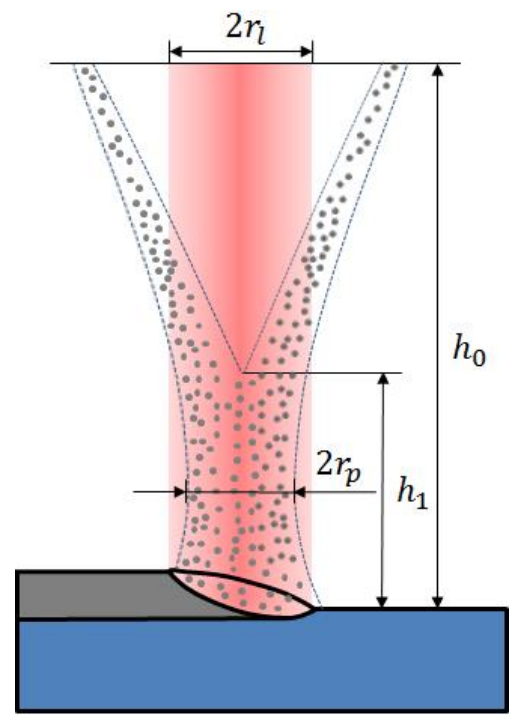

Fig.3 Schematic diagram of laser cladding 

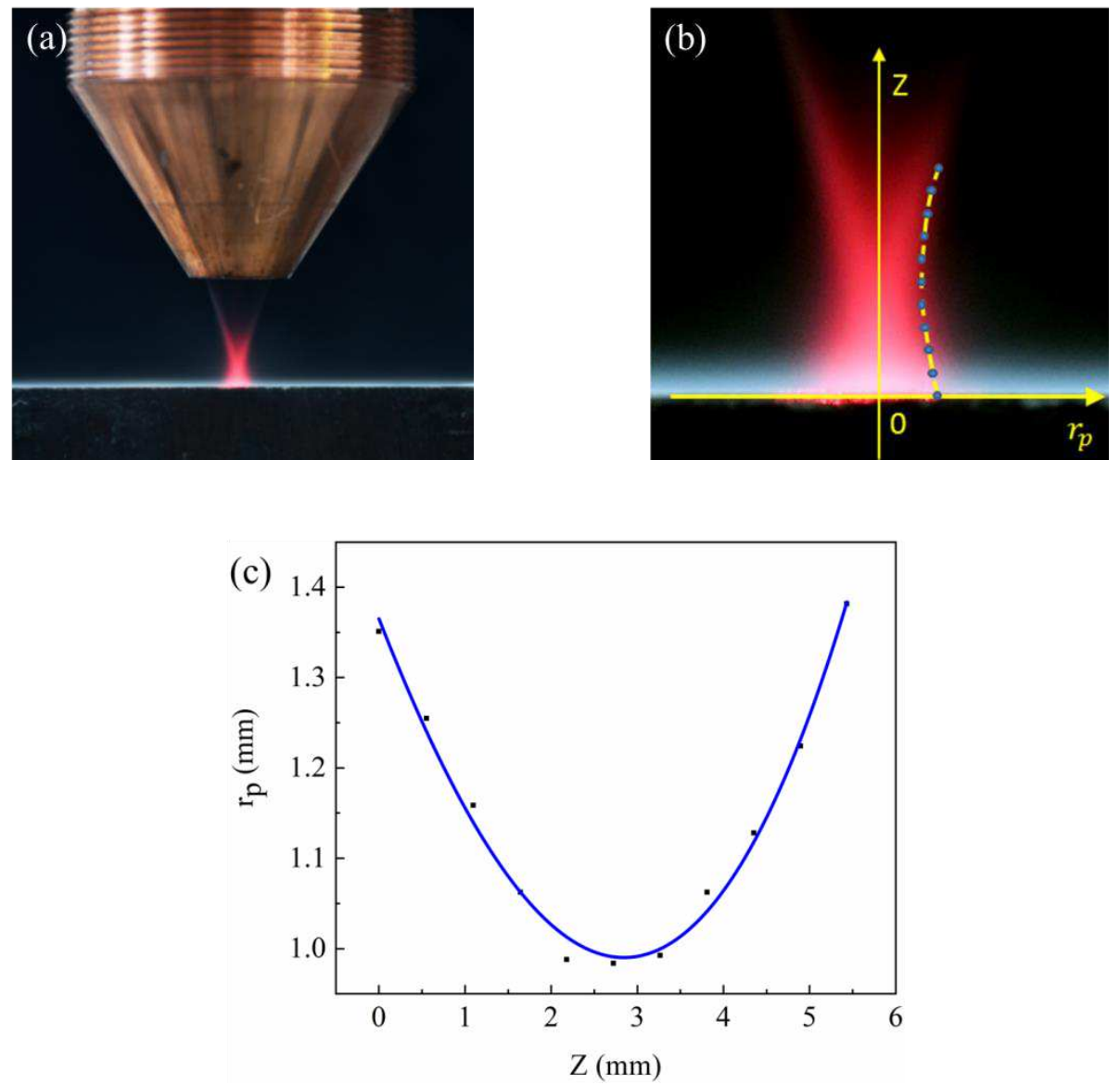

Fig.4 Determination of the powder flow radius relationship (a) Original image of the camera (b) Extracting data points on the contour (c) Fitting curve 


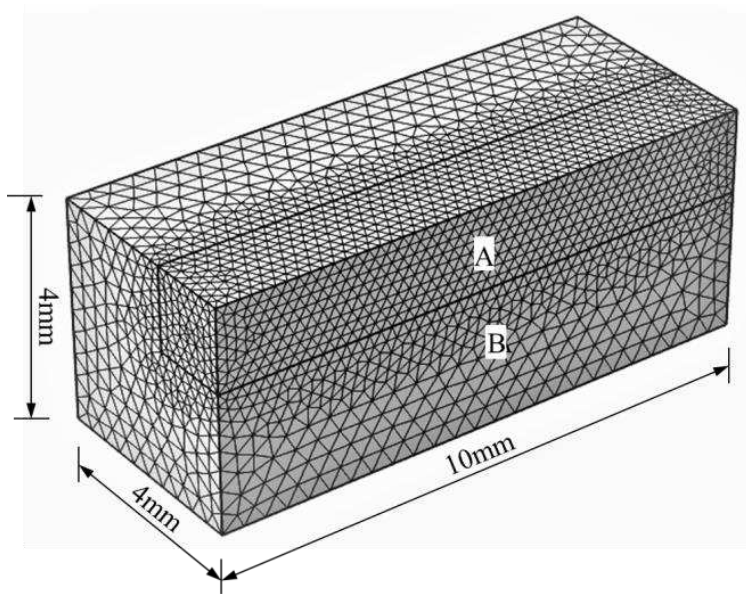

Fig.5 Mesh division of the calculation area 


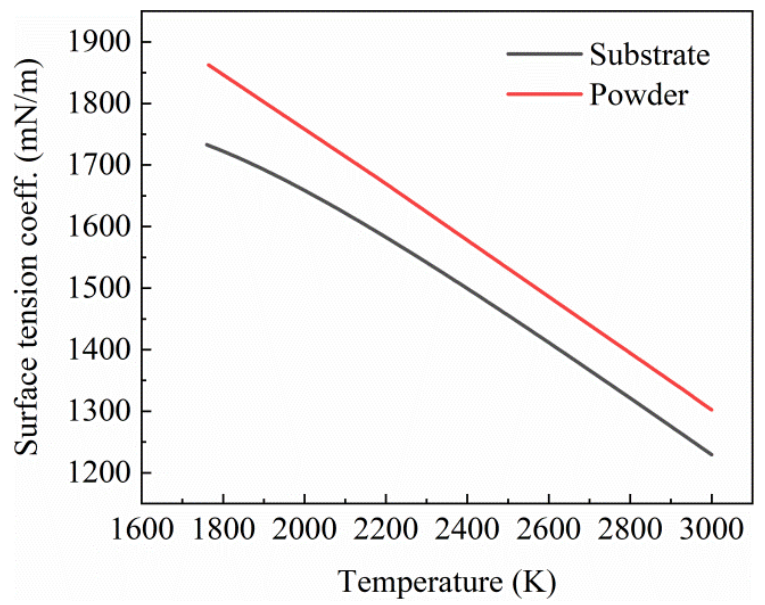

Fig.6 Surface tension coefficient curve of the substrate and powder 

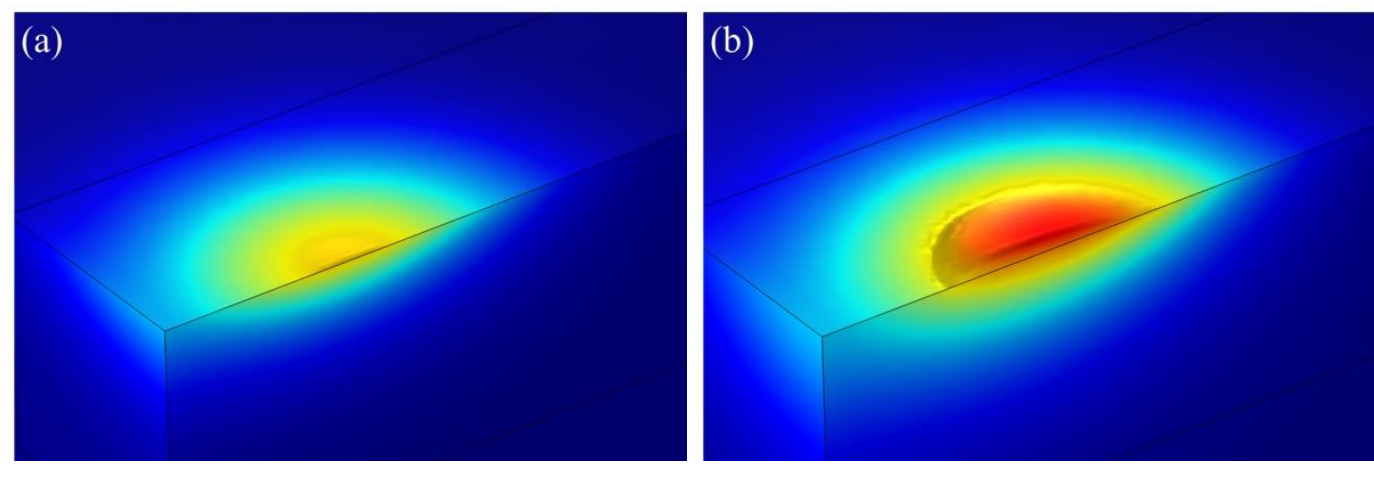

2.4

2.2

2

1.8

1.6

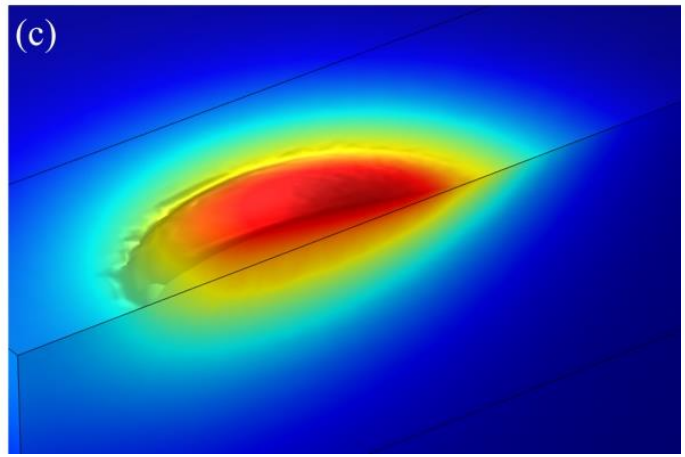

(d)

1.4

1.2

1

0.8

0.6

0.4

Fig.7 Temperature distribution at different moments in the simulation results of exp.1

(a) $30 \mathrm{~ms}(\mathrm{~b}) 50 \mathrm{~ms}(\mathrm{c}) 100 \mathrm{~ms}(\mathrm{~d}) 150 \mathrm{~ms}$ 

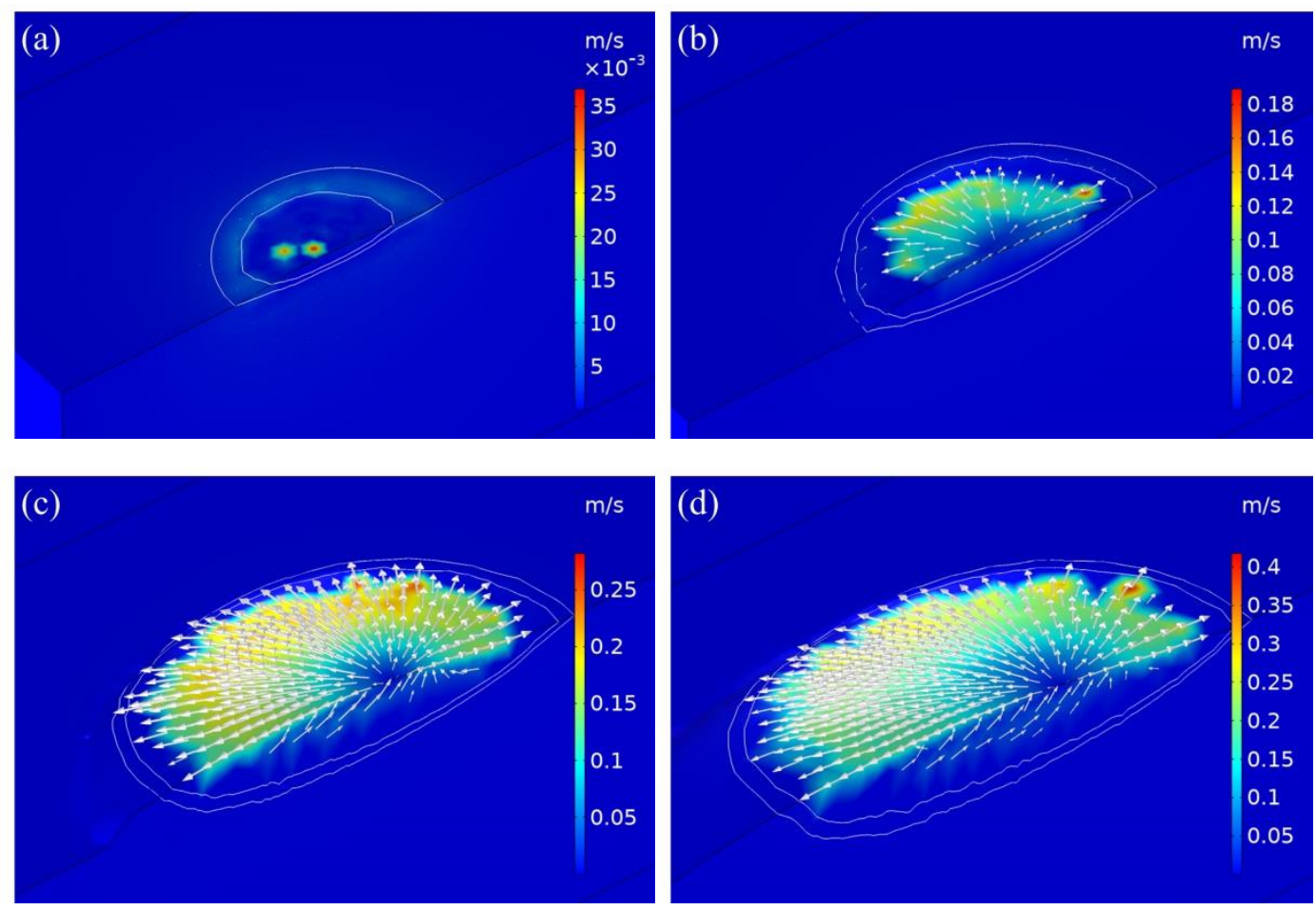

Fig.8Velocity distribution at different moments in the simulation results of exp.1

(a) $30 \mathrm{~ms}(\mathrm{~b}) 50 \mathrm{~ms}(\mathrm{c}) 100 \mathrm{~ms}(\mathrm{~d}) 150 \mathrm{~ms}$ 


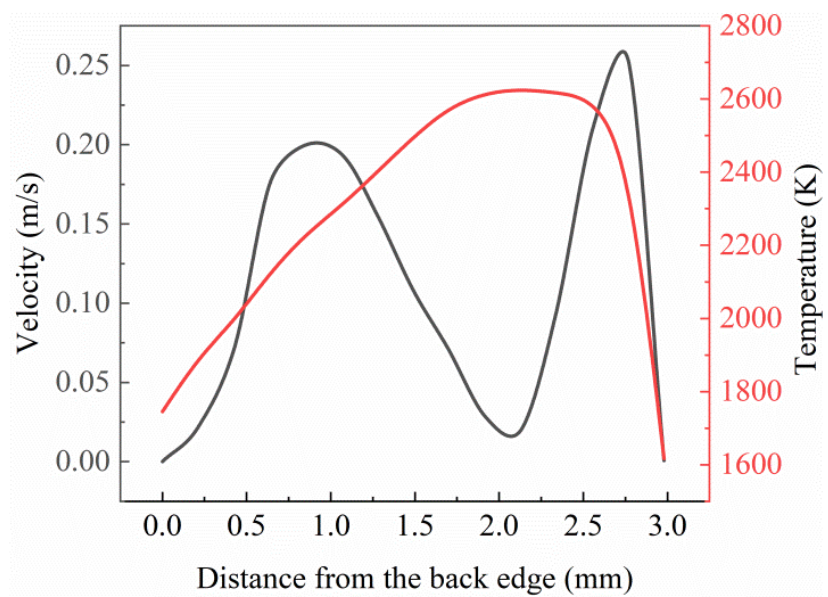

Fig.9 Temperature and velocity distribution curve in the direction of scanning speed on the surface of the melt-pool 
(a)
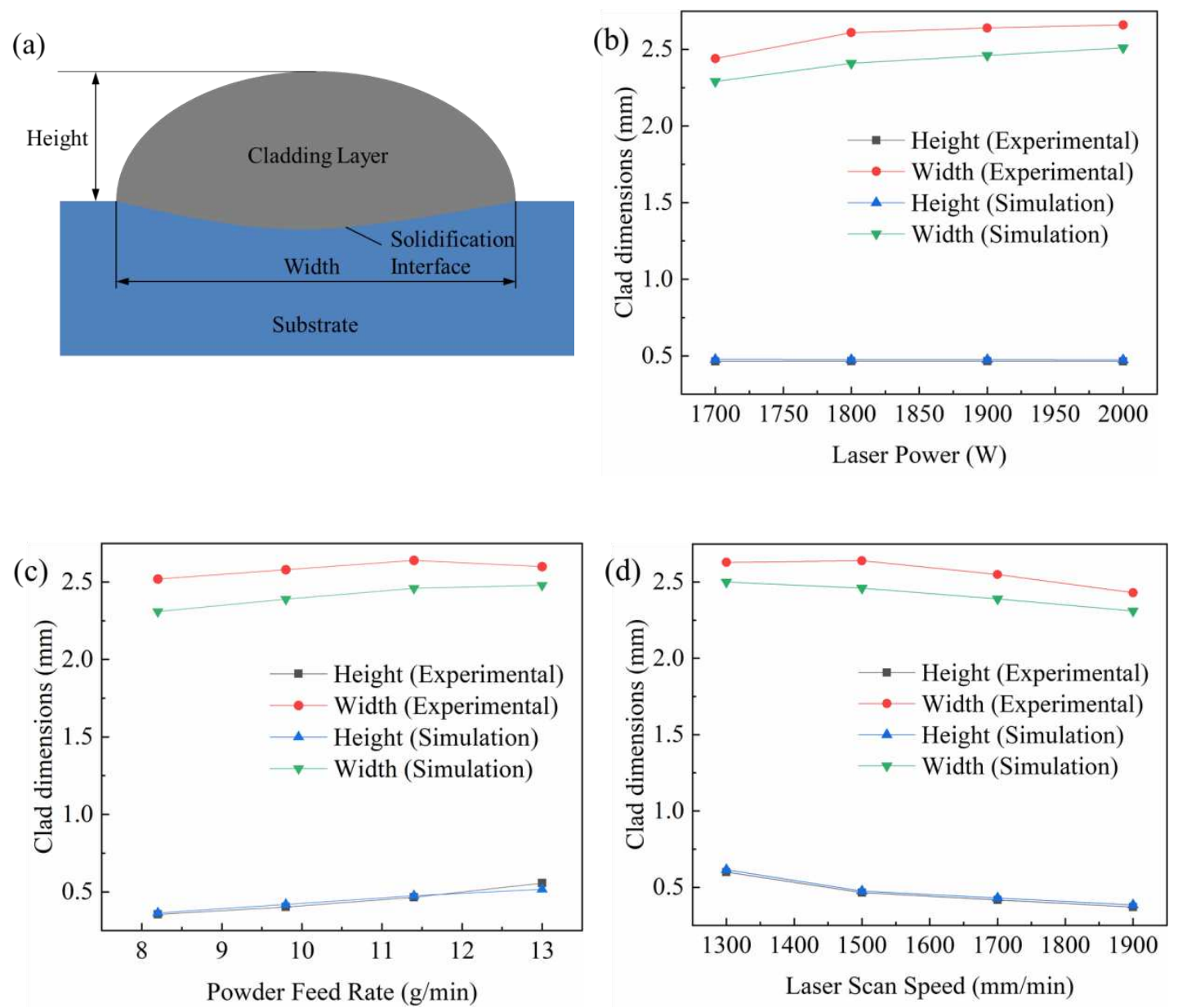

Fig.10. Numerical prediction and experimental results of the dimensions of the deposited single tracks for (a) Schematic cross section (b)varying laser power(c)varying powder feeding rate (d) varying laser scanning speed. 


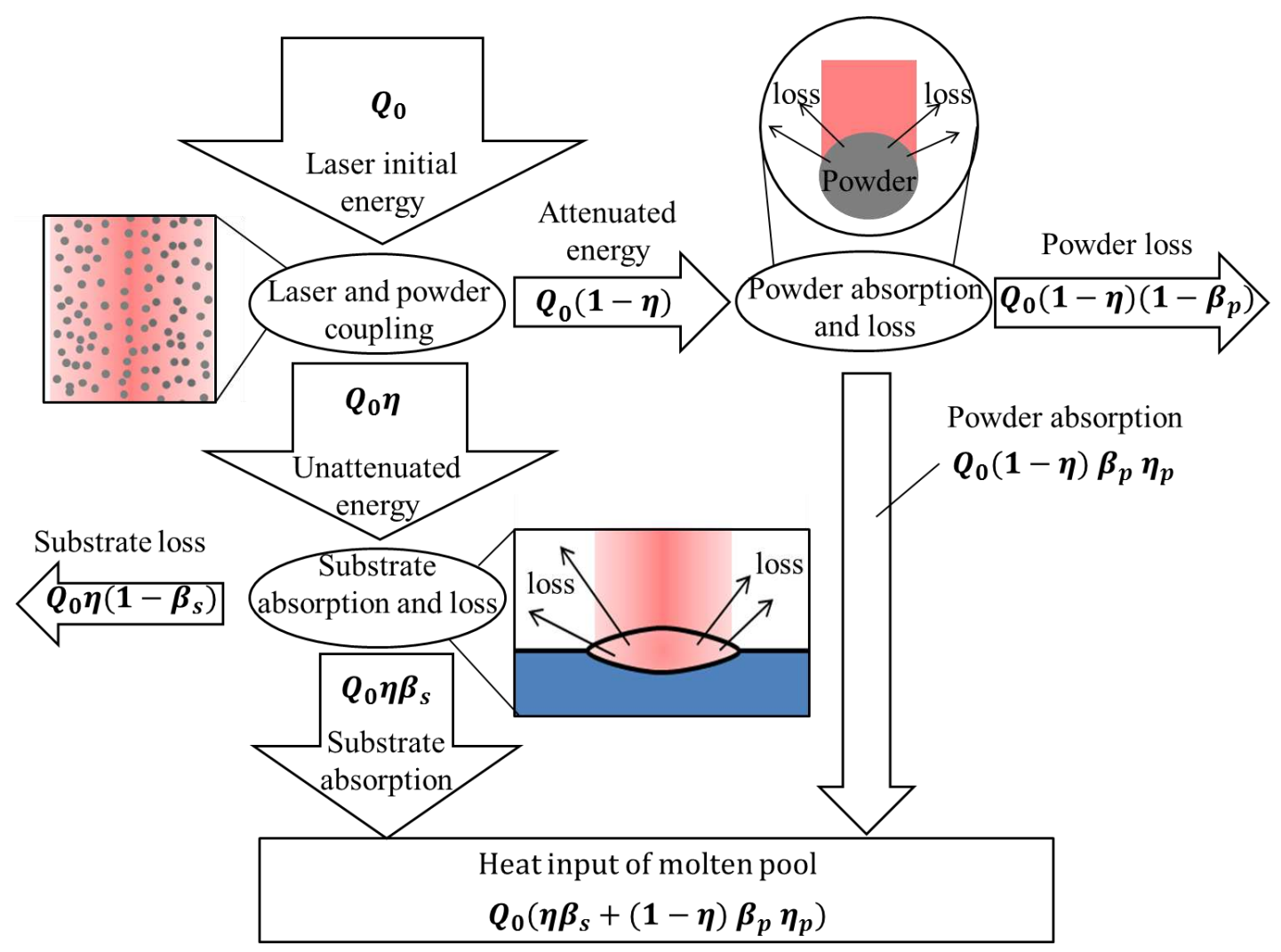

Fig.11 Energy distribution process in the cladding process 


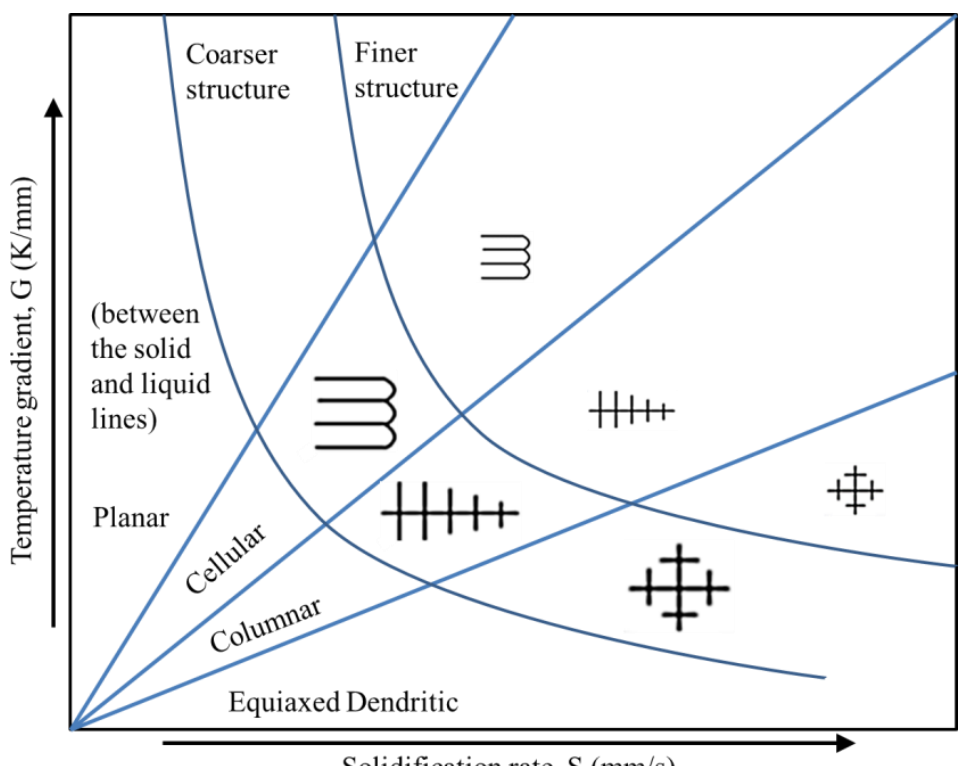

Solidification rate, $\mathrm{S}(\mathrm{mm} / \mathrm{s})$

Fig.12 The influence of $\mathrm{G}$ and $\mathrm{S}$ on the microstructure 


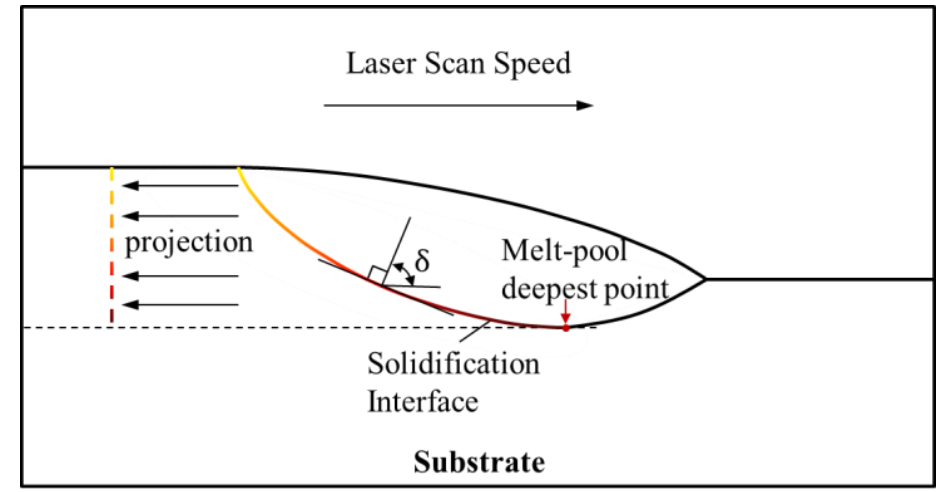

Fig.13 Projection of the solidification interface on the melt-pool symmetry 

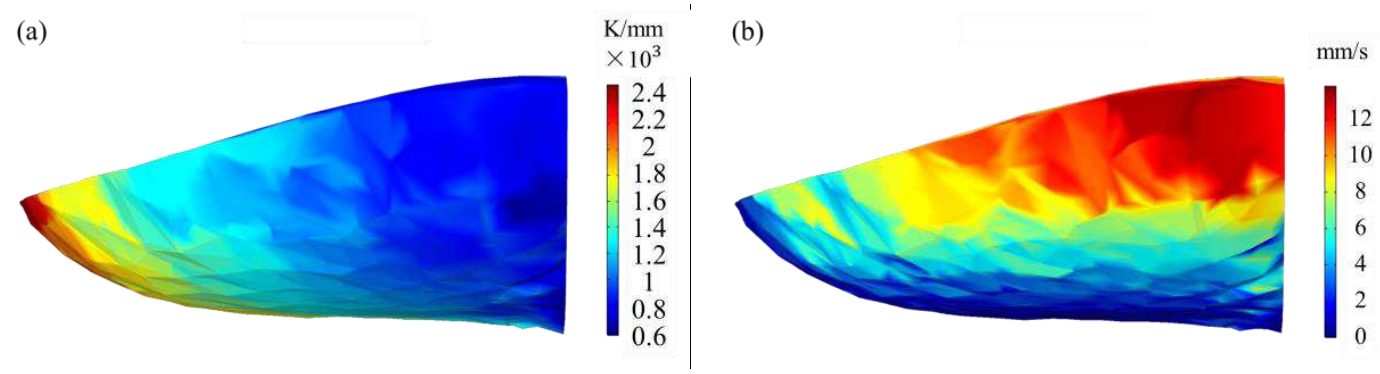

Fig.14 (a)The temperature gradient $\mathrm{G}$ and (b)the solidification rate $\mathrm{S}$ in the calculation results 

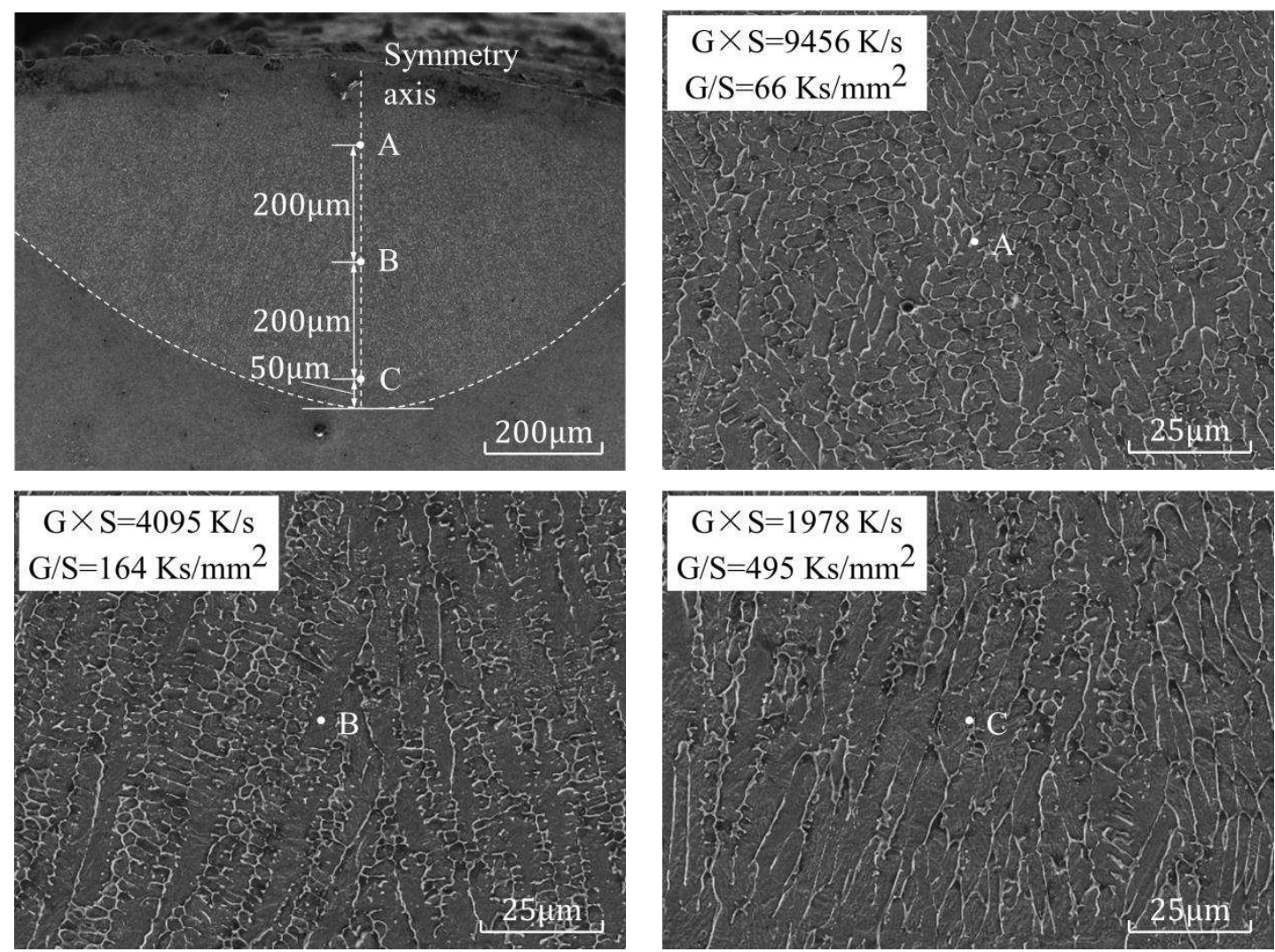

Fig.15 The microstructure of points A, B and C of the cladding layer in exp.No.1 
Table 1 Elemental mass fractions of substrate and powder (wt $\%)$

\begin{tabular}{cccccccccc}
\hline element & $\mathrm{Fe}$ & $\mathrm{C}$ & $\mathrm{Cr}$ & $\mathrm{Ni}$ & $\mathrm{Mn}$ & $\mathrm{Si}$ & $\mathrm{P}$ & $\mathrm{S}$ & $\mathrm{Mo}$ \\
\hline substrate & Bal. & 0.3 & 0.3 & 0.2 & 1.25 & 1.25 & 0.03 & 0.03 & - \\
\hline powder & Bal. & 0.15 & 18 & 2.5 & - & - & - & - & 0.5 \\
\hline
\end{tabular}


Table 2 Process parameters of each experiment

$\begin{array}{cc}\text { Maximum output power of laser } \mathrm{P}_{\max } & 2000 \mathrm{~W} \\ \text { Laser center wavelength } \lambda & 1080 \mathrm{~nm} \\ \text { Laser beam diameter } 2 \mathrm{r}_{l} & 3 \mathrm{~mm} \\ \text { Powder jet diameter } 2 \mathrm{r}_{\mathrm{p}} & 2\left(0.05 \mathrm{z}^{2}-0.28 \mathrm{z}+1.38\right) \\ \text { Carrier powder gas flow } \mathrm{V} & 9 \mathrm{~L} / \mathrm{min} \\ \text { Shield air flow } \mathrm{V}_{\mathrm{p}} & 20 \mathrm{~L} / \mathrm{min} \\ \text { Absorption of the the substrate } \beta_{\mathrm{s}} & \beta_{\mathrm{s}} \\ \text { Absorption of the powder } \beta_{\mathrm{p}} & 0.47 \\ \text { ffective height of light powder coupling } \mathrm{h}_{1} & 5.43 \mathrm{~mm} \\ \text { ance between cladding head and substrate } \mathrm{h}_{0} & 12 \mathrm{~mm}\end{array}$


Table 3 Process parameters of each experiment

\begin{tabular}{cccc}
\hline Expt. no. & Power $P_{0}(\mathrm{~kW})$ & Powder feeding rate $m_{f}(\mathrm{~g} / \mathrm{min})$ & Scanning speed $v_{x}(\mathrm{~mm} / \mathrm{min})$ \\
\hline 1 & 1.9 & 11.4 & 1500 \\
2 & 1.8 & 11.4 & 1500 \\
3 & 1.7 & 11.4 & 1500 \\
4 & 2.0 & 11.4 & 1500 \\
5 & 1.9 & 9.8 & 1500 \\
6 & 1.9 & 8.2 & 1500 \\
7 & 1.9 & 13 & 1500 \\
8 & 1.9 & 11.4 & 1700 \\
9 & 1.9 & 11.4 & 1900 \\
10 & 1.9 & 11.4 & 1300 \\
\hline
\end{tabular}

校对报告

当前使用的样式是 [国家标准GB7714-87]

当前文档包含的题录共 27 条

有 0 条题录存在必填字段内容缺失的问题

所有题录的数据正常 